\title{
Which Treatment in Helicobacter pylori Infection?
}

Marco Manfredi ${ }^{1,2 *}$, Barbara Bizzarri' ${ }^{1}$, Elisabetta Manzali², Alessandro Fugazza1', Pierpacifico Gismondi ${ }^{2}$ and Gian Luigi de’Angelis ${ }^{1,2}$

${ }^{1}$ Gastroenterology and Endoscopy Unit, Azienda Ospedaliero-Universitaria di Parma, University Hospital, Parma, Italy

${ }^{2}$ Department of Pediatrics, "Pietro Barilla" Children's Hospital, Azienda Ospedaliero-Universitaria di Parma, University Hospital, Parma, Italy

\section{Abstract}

For many years in Helicobacter pylori-positive patients, the most used eradication regimen has been the triple therapy, consisting by the association of two antibiotics usually chosen between amoxicillin, clarithromycin and metronidazole.

In recent years because of the increasingly resistance of this therapy, several options have been used. The most innovative regimen is sequential therapy, but maybe bismuth-containing quadruple therapy is the more frequently used worldwide. Other effective treatments are concomitant therapy or quinolone-containing triple therapy.

Moreover, further approaches have been developed such as the hybrid therapy or the quadruple in which three antibiotics are included in a single capsule.

The therapeutic approach for second-line therapy should be based on the regimen used in the first-line treatment trying to obtain the best eradication rate.

Instead, regarding the third-line therapy, the international guidelines recommend the culture-guided approach or in alternative a therapy based on local antimicrobial resistances.

This review attempts to summarize the many possibilities currently available in eradication of Helicobacter pylori infection.

Keywords: Helicobacter pylori infection; Eradication regimens; Firstline therapy; Second-line therapy; Third-line therapy; Adjuvants

\section{Introduction}

Since the original description of Helicobacter pylori ( $H$ pylori) by Marshall and Warren in 1982, gastroenterologists are constantly looking for new therapeutic combinations to get increasingly satisfactory eradication rates [1]. Because of his crucial role in the development of chronic gastritis, gastro duodenal ulcer and gastric cancer, the importance of its eradication is well known and it remains a global health issue also in western countries [2].

In fact, anti- $H$ pylori treatment continues to be a challenge for physicians since bacterial resistance increased worldwide following large use of antibiotics, mainly for respiratory tract infections $[1,3]$. Moreover, $H$ pylori is sensitive to few medications and their widespread use (and, sometimes, abuse) in fighting infections, particularly in the respiratory tract, has led to a reduction in their effectiveness against this bacterium [4]; furthermore, $H$ pylori itself generates pharmacological resistances that differ with geographic area and they compromise successive second and third-line therapies [5-7].

The Maastricht conferences have suggested use of treatment packages consisting of two different regimens designed such that failure of initial therapy would prompt treatment with a second line therapy $[8,9]$.

\section{First-line Therapy}

The main international guidelines $[4,10,11]$ recommend the standard triple therapy (PPI+amoxicillin+clarithromycin-all b.i.d.) as first-line regimen, although its effectiveness is clearly decreasing. Clarithromycin and metronidazole resistance is the most important cause involved in reducing the effectiveness of triple therapy which fluctuates from 72 to $78 \%$ [12-15], lower than the $80 \%$, minimum eradication rate expected for an infectious disease [16].

In the area of clarithromycin-resistance $<10 \%$ (i.e., the Netherland, Sweden, Ireland, Germany, and Malaysia) it's still possible to use standard triple therapy; however it should be abandoned in the areas with clarithromycin resistance $>20 \%$ (i.e., Spain, Turkey, Italy, Alaska, China, and Cameroon) [17,18].

Regarding duration of therapy there is no significant difference between a 7- and 14-day based triple therapy, but it must also be remembered that the longer the therapy is continued, the greater the side effects $[1,4,13]$.

However, a recent study from Japan showed a very good eradication rate $(>90 \%)$ using triple therapy with PPI, amoxicillin and metronidazole [19].

Alternative treatment options for $H$ pylori infection are bismuth containing and non-bismuth containing quadruple therapy (sequential and concomitant) and triple therapy with new drugs such as levofloxacin, moxifloxacin, rifabutin and furazolidone [4]

The Maastricht IV/Florence consensus report recommends bismuth-containing and non-bismuth-containing quadruple therapy (sequential and concomitant) as first-line empirical treatment for $H$ pylori infection in the area of high clarithromycin resistance [4].

Sequential therapy is the most innovative therapeutic change in $H$ pylori infection and it should generally be greater over triple therapy. It consists of five days of PPI+amoxicillin followed by

*Corresponding author: Marco Manfredi, Department of Pediatrics, "Pietro Barilla" Children's Hospital, Azienda Ospedaliero-Universitaria di Parma, University Hospital, Via Gramsci 14, 43126 Parma, Italy, E-mail: marco.manfredi8@gmail.com

Received September 30, 2013; Accepted November 05, 2013; Published November 12, 2013

Citation: Manfredi M, Bizzarri B, Manzali E, Fugazza A, Gismondi P, et al (2013) Which Treatment in Helicobacter pylori Infection? Clin Exp Pharmacol 3: 139. doi:10.4172/2161-1459.1000139

Copyright: (C) 2013 Manfredi M, et al. This is an open-access article distributed under the terms of the Creative Commons Attribution License, which permits unrestricted use, distribution, and reproduction in any medium, provided the original author and source are credited. 
PPI+claritromycin+tinidazole for the next five days. Multicenter studies carried out in different countries (Taiwan, Italy, Morocco, China...) have confirmed the advantage for the sequential regimen over standard triple therapy [20]. According to some authors this treatment could be much more complex in terms of medication requirements, because of changing drugs during a treatment course might reduce patient compliance; however, it has been shown that in clinical practice, patients who are non-compliant with regard to taking drugs are no different than those who take triple therapy [21].

Non-bismuth quadruple therapy, also termed "concomitant" has been proposed and it consists in four drugs regimen containing PPI, clarithromycin, amoxicillin and metronidazole, which are all given for the entire duration of therapy (from 5 to 10 days). Recent studies showed advantages in terms of compliance and eradication rates which amount to $94.9 \%$ [20].

Recently, Hsu and colleagues, has reported an "hybrid therapy" (14day therapy) consisting of a combination of sequential and concomitant therapy in particular PPI and amoxicillin for 7 days followed by a concomitant therapy for the next 7 days [3].

There were no differences in eradication rates between 14-day hybrid and 14-day concomitant therapies, but the compliance is better with the hybrid than the concomitant regimen. Furthermore, this novel therapy also achieved an excellent eradication rate, almost 100\% [3].

In recent years bismuth-containing quadruple therapy which were commonly used in 80-90's, has been rediscovered. Because of their abandonment for several years, now bismuth salts are achieving excellent results in eradication of $H$ pylori infection. In fact, this therapy as first-line regimen demonstrated an eradication rate of $>90 \%$; however the optimal treatment duration remains unclear but a 10-14 day course is most commonly employed in clinical practice [3].

Triple therapy with new drugs such as levofloxacin, gemifloxacin, moxifloxacin is also studied for the first or second line treatment. Quinolone-containing triple therapy might be considered in populations with claritromycin resistance greater than $15-20 \%$ and quinolone resistance lower than $10 \%$. This therapy showed an eradication rate ranged between $72-96 \%$ across studies [22].

A novel therapeutic approach consisting of quadruple therapy with PPI plus a single capsule containing three antibiotics (bismuth subcitrate, metronidazole and tetracycline) has recently been developed. This regimen achieved a good eradication rate (92-93\%) in the 10-day course of therapy [23] which became excellent (97.1\%) when therapy was prolonged for two weeks [24]. This format offers the advantages of taking three antibiotics in a single capsule and overcoming resistance to metronidazole. The side effects seem to be similar to those of the standard triple therapy.

\section{Second-line Therapy}

Choice of second-line therapy depends on what has been used as first-line; therefore it should use different constituent antibiotics. Quinolone-based, bismuth-based and non-bismuth-based treatments are all acceptable options for second-line therapy [4,10,11,25].

The best second-line therapy remains unclear, however the current Maastricht-IV guidelines suggest that after failure of a PPIclarithromycin-containing treatment, either a bismuth-containing quadruple therapy or levofloxacin-containing triple therapy is recommended [4].

Manfredi et al. had chosen a 10-day levofloxacin-containing triple therapy as second-line after a course of sequential therapy, providing a good cumulative eradication rate of the $H$ pylori infection, at least in northern Italy, in only two rounds [26].

However, a recent study suggested to use the best locally available therapy for both first- and second-line regimen for a period of 14 days, avoiding levofloxacin in areas where $H$ pylori fluoroquinolone resistance is high. Anyway, the final goal should be to achieve an eradication rate of at least $90 \%$ with second-line therapy [25].

Currently a standard empirical third-line therapy is lacking. The Maastricht IV/Florence Consensus Report recommends using bacterial culture with antimicrobial sensitivity test to select antibiotics in the third-line regimen.

In this regards, three interesting studies from China [27], Taiwan [28] and Italy [29] have shown promising results through this strategy. Overall, $H$ pylori eradication was obtained in $90 \%$ of subjects treated by culture-guided therapy.

Several years ago our groups achieved a better eradication rate treating a group of children with culture-based tailored therapy than those treated to empirical triple therapy [30].

In alternative, international guidelines recommend an empirical therapy based on local antibiotic resistances. A 10 days quadruple therapy (PPI+bismuth subcitrate+amoxicillin+levofloxacin) achieved a good eradication rate of $84 \%$ [31].

Also, quadruple furazolidone-containing therapy is another effective approach to treat refractory $H$ pylori infection. This treatment (PPI+bismuth salts+furazolidone+tetracycline for 7 days) achieved a very good eradication rate of $90 \%$ [32].

Eradicating $H$ pylori infection, we cannot forget the high incidence of treatment-related side effects (such as dysgeusia with a metallic taste, diarrhea, nausea, epigastric discomfort), due to modification of the intestinal microbiota as a result of antibiotic use [2,33].

Several meta-analyses have demonstrated that the addition of adjuvants, mainly Lactobacillus spp, Bifidobacterium spp, Saccharomyces spp and Bacillus spp, reduce eradication-related side effects and then improve patient's compliance $[33,34]$.

However, data on improvement of $H$ pylori eradication rate by probiotics are still conflicting. Several studies demonstrated an increase in eradication rates but others showed similar eradication rates using probiotics than placebo. Perhaps, these differences are due to different strains used and various treatment durations of probiotics among studies [3].

\section{Conclusion}

Helicobacter pylori are one of the most common infections in humans causing several gastrointestinal diseases such as gastritis, peptic ulcer, and gastric cancer. For this reasons, gastroenterologists have been trying to knock it down since its discovery.

Over all these years, we have realized that the eradication of this infection is not so easy to get.

The goal of $H$ pylori therapy should be to cure all patients with therapies achieving at least $90 \%$, and preferably $95 \%$ or more, cure rates. The therapy of choice should be the one that offers the highest eradication rate and thus produces the smallest proportion of patients requiring repetition of treatment [35].

During the last years, the triple therapy is evidently decreased of 
Citation: Manfredi M, Bizzarri B, Manzali E, Fugazza A, Gismondi P, et al. (2013) Which Treatment in Helicobacter pylori Infection?. Clin Exp Pharmacol 3: 139. doi:10.4172/2161-1459.1000139

Page 3 of 3

effectiveness with very low eradication rates. For these reasons many alternative treatment approaches have been developed.

Treatment failure increases the percentage of second-line and third-line therapies, raising the expense of treatment and the number of patients who have to undergo many antibiotic treatments. So, if you must choose between two therapies, it is illogical and unethical to advise using the one with the lower eradication rate as the initial therapy [25].

Therefore in conclusion, the best eradication therapy of $H$ pylori infection should be based on antimicrobial susceptibility. In this regards, nowadays, molecular methods from biopsies (real-time PCR and FISH) have become one of the most promising techniques than culture [36].

Alternatively, if antimicrobial susceptibility tests are not available, empirical therapy based on local antibiotic resistance still remains the best therapeutic option.

\section{References}

1. Manfredi M, de'Angelis GL (2013) Eradication of Helicobacter Pylori: In Search of a Better Therapy. Clin Microbial 1: e101.

2. Malfertheiner P, Megraud F, O'Morain C, Bazzoli F, El-Omar E, et al. (2007) Current concepts in the management of Helicobacter pylori infection: the Maastricht III Consensus Report. Gut 56: 772-781.

3. Ping-I Hsu, Sung-Shuo Kao (2013) Many Drugs for Which Association? In Marco Manfredi and Gian Luigi de'Angelis eds, "Helicobacter pylori: Detection Methods, Diseases, and Health Implications" Chapter 20, Nova Science Publishers, NY, USA.

4. Malfertheiner P, Megraud F, O'Morain CA, Atherton J, Axon AT, et al. (2012) Management of Helicobacter pylori infection--the Maastricht IV/ Florence Consensus Report. Gut 61: 646-664.

5. Megraud F, Kist M, Lopez Brea M, Hirschl A, Andersen LP, et al. (2011) Surveillance of Helicobacter pylori resistance to antibiotics in Europe 20082009. Gastroenterol 140: S312.

6. Kawai T, Yamagishi T, Yagi K, Kataoka M, Kawakami K, et al. (2008) Tailored eradication therapy based on fecal Helicobacter pylori clarithromycin sensitivities. J Gastroenterol Hepatol 23: S171-174.

7. Tay CY, Windsor HM, Thirriot F, Lu W, Conway C, et al. (2012) Helicobacter pylori eradication in Western Australia using novel quadruple therapy combinations. Aliment Pharmacol Ther 36: 1076-1083.

8. Lee YC, Wu HM, Chen TH, Liu TY, Chiu HM, et al. (2006) A community-based study of Helicobacter pylori therapy using the strategy of test, treat, retest, and re-treat initial treatment failures. Helicobacter 11: 418-424.

9. Rokkas T, Sechopoulos P, Robotis I, Margantinis G, Pistiolas D (2009) Cumulative $\mathrm{H}$. pylori eradication rates in clinical practice by adopting first and second-line regimens proposed by the Maastricht III consensus and a third-line empirical regimen. Am J Gastroenterol 104: 21-25.

10. Fock KM, Katelaris P, Sugano K, Ang TL, Hunt R, et al. (2009) Second AsiaPacific Consensus Guidelines for Helicobacter pylori infection. J Gastroenterol Hepatol 24: 1587-1600.

11. Chey WD, Wong BC; Practice Parameters Committee of the American College of Gastroenterology (2007) American College of Gastroenterology guideline on the management of Helicobacter pylori infection. Am J Gastroenterol 102 1808-1825.

12. Egan BJ, Katicic M, O'Connor HJ, O'Morain CA (2007) Treatment of Helicobacter pylori. Helicobacter 12 Suppl 1: 31-37

13. Vakil N, Megraud F (2007) Eradication therapy for Helicobacter pylori. Gastroenterology 133: 985-1001.

14. Zullo A, Vaira D, Vakil N, Hassan C, Gatta L, et al. (2003) High eradication rates of Helicobacter pylori with a new sequential treatment. Aliment Pharmacol Ther 17: 719-726

15. Vaira D, Zullo A, Vakil N, Gatta L, Ricci C, et al. (2007) Sequential therapy versus standard triple-drug therapy for Helicobacter pylori eradication: a randomized trial. Ann Intern Med 146: 556-563.
16. Egan BJ, Katicic M, O'Connor HJ, O'Morain CA (2007) Treatment of Helicobacter pylori. Helicobacter 12: 31-37.

17. Gumurdulu Y, Serin E, Ozer B, Kayaselcuk F, Ozsahin K, et al. (2004) Low eradication rate of Helicobacter pylori with triple 7-14 days and quadriple therapy in Turkey. World J Gastroenterol 10: 668-671.

18. De Francesco V, Margiotta M, Zullo A, Hassan C, Giorgio F, et al. (2007) Prevalence of primary clarithromycin resistance in Helicobacter pylori strains over a 15 year period in Italy. J Antimicrob Chemother 59: 783-785.

19. Sugizaki K, Sakata Y, Arai T, Furuhata Y, linuma N, et al. (2012) A multicenter prospective observational study of triple therapy with rabeprazole, amoxicillin and metronidazole for Helicobacter pylori in Japan. Intern Med 51: 3103-3108.

20. O'Connor A, Molina-Infante J, Gisbert JP, O'Morain C (2013) Treatment of Helicobacter pylori infection 2013. Helicobacter 18 Suppl 1: 58-65.

21. Nimish V (2007) New guidelines for Helicobacter pylori: applying them to your practice. Rev Gastroenterol Disord 7: 111-114.

22. Berning M, Krasz S, Miehlke S (2011) Should quinolones come first in Helicobacter pylori therapy? Therap Adv Gastroenterol 4: 103-114.

23. Malfertheiner P, Bazzoli F, Delchier JC, Celiñski K, Giguère M, et al. (2011) Pylera Study Group. Helicobacter pylori eradication with a capsule containing bismuth subcitrate potassium, metronidazole, and tetracycline given with omeprazole versus clarithromycin-based triple therapy: a randomised, openlabel, non-inferiority, phase 3 trial. Lancet 377: 905-913.

24. Salazar CO, Cardenas VM, Reddy RK, Dominguez DC, Snyder LK, et al. (2012) Greater than $95 \%$ success with 14-day bismuth quadruple anti- Helicobacter pylori therapy: a pilot study in US Hispanics. Helicobacter 17: 382-390.

25. Graham DY, Calvet X (2012) Guide regarding choice of second-line therapy to obtain a high cumulative cure rate. Helicobacter 17: 243-245.

26. Manfredi M, Bizzarri B, de'Angelis GL (2012) Helicobacter pylori infection sequential therapy followed by levofloxacin-containing triple therapy provides a good cumulative eradication rate. Helicobacter 17: 246-253.

27. Liang X, Xu X, Zheng Q (2013) Efficacy of Bismuth-containing quadruple therapies for claritromicin-, metronidazole- and fluorochinolone-resistance Helicobacter pylori infections in a prospective study. Clin Gastroenterol Hepatol 11: 802-807.

28. Liou JM, Chen CC, Chang CY, Chen MJ, Fang YJ, et al. (2013) Efficacy of genotypic resistance-guided sequential therapy in the third-line treatment of refractory Helicobacter pylori infection: a multicentre clinical trial. J Antimicrob Chemother 68: 450-456.

29. Fiorini G, Vakil N, Zullo A, Saracino IM, Castelli V, et al. (2013) Culture-based selection therapy for patients who did not respond to previous treatment for Helicobacter pylori infection. Clin Gastroenterol Hepatol 11: 507-510.

30. Street ME, Caruana P, Caffarelli C, Magliani W, Manfredi M, et al. (2001) Antibiotic resistance and antibiotic sensitivity based treatment in Helicobacter pylori infection: advantages and outcome. Arch Dis Child 84: 419-422.

31. Hsu PI, Wu DC, Chen A, Peng NJ, Tseng HH, et al. (2008) Quadruple rescue therapy for Helicobacter pylori infection after two treatment failures. Eur $\mathrm{J}$ Clin Invest 38: 404-409.

32. Treiber G, Ammon S, Malfertheiner P, Klotz U (2002) Impact of furazolidonebased quadruple therapy for eradication of Helicobacter pylori after previous treatment failures. Helicobacter 7: 225-231.

33. Manfredi M, Bizzarri B, Sacchero RI, Maccari S, Calabrese L, et al. (2012) Helicobacter pylori infection in clinical practice: probiotics and a combination of probiotics + lactoferrin improve compliance, but not eradication, in sequential therapy. Helicobacter 17: 254-263.

34. Cremonini F, Di Caro S, Covino M, Armuzzi A, Gabrielli M, et al. (2002) Effect of different probiotic preparations on anti-helicobacter pylori therapy-related side effects: a parallel group, triple blind, placebo-controlled study. Am J Gastroenterol 97: 2744-2749.

35. Graham DY, Rimbara E (2012) Helicobacter pylori therapy in the west Japanese J Helicobacter Res 13: 4-9.

36. Almeida C, Azevedo NF, Joao Vieira M (2013) Unusual techniques: Identification of $H$. pylori from biopsies (Culture, PCR and FISH), Chapter 4. In Marco Manfred and Gian Luigi de'Angelis (eds) "Helicobacter pylori: Detection Methods, Diseases, and Health Implications". Nova Science Publishers, NY, USA. 